\title{
Effect of Different Formulations and Application Methods of Coral Calcium on its Remineralization Ability on Carious Enamel
}

\author{
Ali Abdelnabi ${ }^{1}$, Nermeen Kamal Hamza ${ }^{2}$, Ola M. El-Borady ${ }^{3}$, Tamer M. Hamdy ${ }^{1 *}$ \\ ${ }^{1}$ Department of Restorative and Dental Materials, National Research Centre, Giza, Egypt; ${ }^{2}$ Department of Operative Dentistry, \\ MSA University, $6^{\text {th }}$ of October City, Egypt; ${ }^{3}$ Institute of Nanoscience and Nanotechnology, Kafr El-Shaikh University, Kafr \\ El-Shaikh, Egypt
}

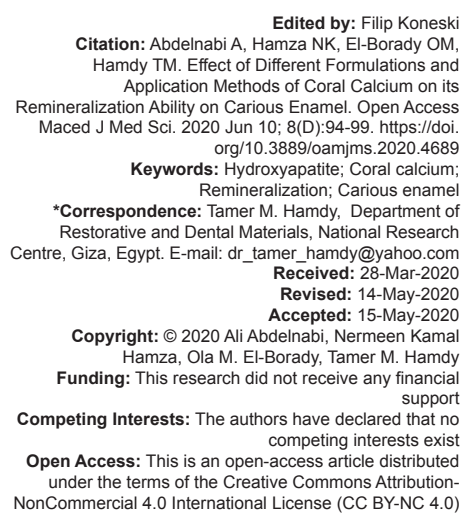

Introduction

Dental caries is one of the most widespread diseases which lead to the destruction of tooth structure by acid production by oral cariogenic pathogens due to carbohydrate fermentation [1], [2], [3]. The natural remineralization procedure of enamel depends on the salivary calcium and phosphate ions in addition to fluoride [4], [5]. The strategy of dental caries in demineralization is performed through secretion of acid by bacteria in dental plaque biofilms [6]. Dental caries is a cyclic disease composed of alternating cycles of de- and re-mineralization. The process of de- and re-mineralization is controlled by the degree of acid attack versus the saturation of saliva with apatite minerals [7]. Providing the proper change in conditions, re-mineralization will dominate, resulting in lesion repair. To stimulate lesion re-mineralization, elevated calcium and phosphate concentration in contact to the de-mineralized lesion will enhance the process [8].
Dental enamel is composed of approximately 96 weight\% of minerals, similar to hydroxyapatite $(\mathrm{HA})$ $\mathrm{Ca}_{10}\left(\mathrm{Po}_{4}\right)_{6}(\mathrm{OH})_{2}$. The structural nature of apatite crystal means that they allow many substitutions in its crystal lattice without changing identity. In apatite crystals, the substitution of calcium ions may occur by ions such as sodium, zinc, and strontium, while phosphate in the lattice can be substituted by carbonate. The process of interaction between enamel and oral fluids is ruled by the dissolution behavior of the apatite mineral, of which enamel is composed [9], [10].

HA nanoparticles are recently considered as an enamel substitute due to chemical similarity. Many dental studies recommend to remineralize enamel using HA or amorphous calcium phosphate (ACP) [11], [12]. Calcium-based compounds could be efficiently used for healing of biological dental tissues [13], [14], [15], [16]. Despite the complicated hierarchical structure of enamel, it is now clear that the main structure of enamel is generally consists of $20-40 \mathrm{~nm}$ HA nanoparticles. $\mathrm{HA}$ particles in nanosize could serve as an analog compound that mimics the normal biological apatite 
[17], [18], [19]. The use of the biomimetic technical concept suggests that the localized repair of enamel surfaces can be achieved through using the analog compound of the basic structure of enamel [19], [20].

The HA nanoparticles can precipitate onto the enamel surface strongly and can even prevent further demineralization [20]. It has also been shown that nanohydroxyapatite 10-20 nm diameter and $60-80 \mathrm{~nm}$ length can enhance the penetration of crystals into the inter-prismatic protein, resulting in re-mineralization of the superficial layer of the carious lesion and reversing the progression of initial carious lesions [21].

Availability of calcium comes in many forms calcium carbonate, calcium citrate, calcium phosphate, and coral calcium is a form of calcium carbonate. Coral calcium is calcium sourced from fossilized coral calcium sources and is the most common form of calcium on the planet. A study showed the ability of coral calcium to enhance calcium deposition in bone and helping to heal bone fractures. It has also launched in the market as a dietary supplement to prevent osteoporosis. The effect of coral calcium topical application on enamel and its remineralizing capability on teeth is not yet adequately studied. Therefore, the aim of the current study is to compare the remineralization effect of coral calcium in different formulations and application methods.

\section{Materials and Methods}

Both HA nanoparticles, coral calcium, and mixtures of them in different concentrations were used as a remineralizing agent. The coral calcium was delivered from (Coral Calcium Plus, Bone Health, Now Foods, USA).

\section{Preparation and characterization of $H A$ nanoparticles}

HA nanoparticles were prepared through the wet chemical process [15], [22]. The precursors use calcium nitrate $\left[\mathrm{Ca}\left(\mathrm{NO}_{3}\right)_{2}\right]$ and ammonium phosphate $\left[\left(\mathrm{NH}_{4}\right)_{3} \mathrm{PO}_{4}\right], \mathrm{NH}_{4} \mathrm{OH}$ was used as a precipitating agent. First, an aqueous solution of $\mathrm{Ca}\left(\mathrm{NO}_{3}\right)_{2}(0.042 \mathrm{M})$ was freshly prepared and put in a $500 \mathrm{ml}$ three-neck flask. Another two separate solutions in two different flasks of $\left(\mathrm{NH}_{4}\right)_{3} \mathrm{PO}_{4}(0.025 \mathrm{M})$ and $\mathrm{NH}_{4} \mathrm{OH}$ were also prepared. The last two solutions were added dropwise through to the $\mathrm{Ca}\left(\mathrm{NO}_{3}\right)_{2}$ solution while the $\mathrm{pH}$ was monitored at 10 . Through the addition process, a white precipitate was formed that taken as an indication for the formation of HA nanoparticles. Finally, all the HA powders obtained were sintered at $300^{\circ} \mathrm{C}$. The $\mathrm{HA}$ with $\mathrm{Ca} / \mathrm{P}$ ratio equal 1.67 was prepared according to the following equation: $10 \mathrm{Ca}\left(\mathrm{NO}_{3}\right)_{2} \cdot 4 \mathrm{H}_{2} \mathrm{O}+6\left(\mathrm{NH}_{4}\right)_{2} \mathrm{HPO}_{4}+8 \mathrm{NH}_{4} \mathrm{OH}=\mathrm{Ca}_{10}\left(\mathrm{PO}_{4}\right)$ $6(\mathrm{OH})_{2}+20 \mathrm{NH}_{4} \mathrm{NO}_{3} \cdot 46 \mathrm{H}_{2} \mathrm{O}$
Characterization of the prepared $\mathrm{HA}$ nanoparticles was done through transmission electron microscopy (TEM) instrument (Model JOEL JEM-2010) operating by accelerating voltage of $200 \mathrm{kV}$ equipped using Gatan Digital Camera (Model Erlangshen ES500). The Fourier transform infrared (FT-IR) analysis was carried out using a spectrometer (JASCO) in the scanning range from 4000 to $400 \mathrm{~cm}^{-1}$ for analysis of the structural composition of the prepared HA nanoparticles as well as the coral calcium, the mixture of them.

\section{Preparation of the remineralizing agent}

A total of 70 sound enamel disc specimens was obtained from the collection of 35 extracted human molars, tooth examined under stereomicroscope (Olympus SZH10 - Olympus Optical do Brasil, Ltda., São Paulo, SP, Brazil), and any tooth having cracks or flaws was discarded, then it was cleaned and polished by means of a manual dental scaler, polishing paste, and rotating brush. Roots were removed by a diamond stone and pulp tissues were eliminated. Teeth were cut by a microtome (ISOMET TM 1000, Buehler) to obtain 70 sound enamel disc specimens. Discs were coated with acid-resistant colored varnish except for a $1 \mathrm{~mm}$ diameter area and stored in distilled water.

\section{Remineralization analysis}

Initial mineral content examination for calcium mineral content was measured before any treatment via scanning electron microscope coupled with energy dispersive analysis of X-rays (EDAX). The procedure of demineralization (artificial caries) was induced by individual immersion of the specimens in $10 \mathrm{ml}$ of a demineralizing solution of $\mathrm{pH} 4.3$ at $37^{\circ} \mathrm{C}$ for 14 days where the solution was changed every other day. The solution contained: $0.1 \mathrm{~mol} / \mathrm{l}$ lactic acid buffer, $0.2 \%$ polyacrylic acid (Carbopol $\circledast 980$ - DEG Importadora de Produtos Químicos Ltda., São Paulo, SP, Brazil), and 0.03 ppm F (Gen-phos HA - Hospitália Cirúrgica Catarinense Ltda., Florianópolis Santa Catarina, Brazil) at $\mathrm{pH}$ 5.0. To avoid fungal growth in the demineralizing solution, $0.18 \%$ methylparaben was added to it. Calcium mineral content was measured after induction of demineralization (artificial caries) using EDAX.

Remineralizing gel was prepared by the addition of different formulation of coral calcium (cc) to cellulose gel purchased from Sigma Aldrich. The specimen was divided equally into ten groups, where Groups 1-3 used 10,20 , and 30 weight $\%$ (wt.\%) coral calcium gel, respectively; Groups 4-6 used 10, 20, and $30 \mathrm{wt} . \%$ coral calcium and nanohydroxyapatite mix gel; Groups 7-9 used 10, 20, and $30 \mathrm{wt} . \%$ coral calcium with argon laser activation (5 s); and Group 10 (control group) without using a remineralizing agent. The final examination of the calcium mineral content was re-measured after the remineralization. The calcium levels were calculated, 
mean values were obtained, and percentage of change was calculated to detect the remineralization ability of each gel. Data were explored for normality using KolmogorovSmirnov and Shapiro-Wilk tests and showed parametric (normal) distribution. One-way ANOVA followed by Tukey post hoc test was used to compare between more than two groups in non-related samples.

\section{Results}

The TEM image of the prepared HAnanoparticles was represented in Figure 1. It was observed that HA particles were created as rod shape flakes with an average size (80-100 nm length) and (15-20 nm width).

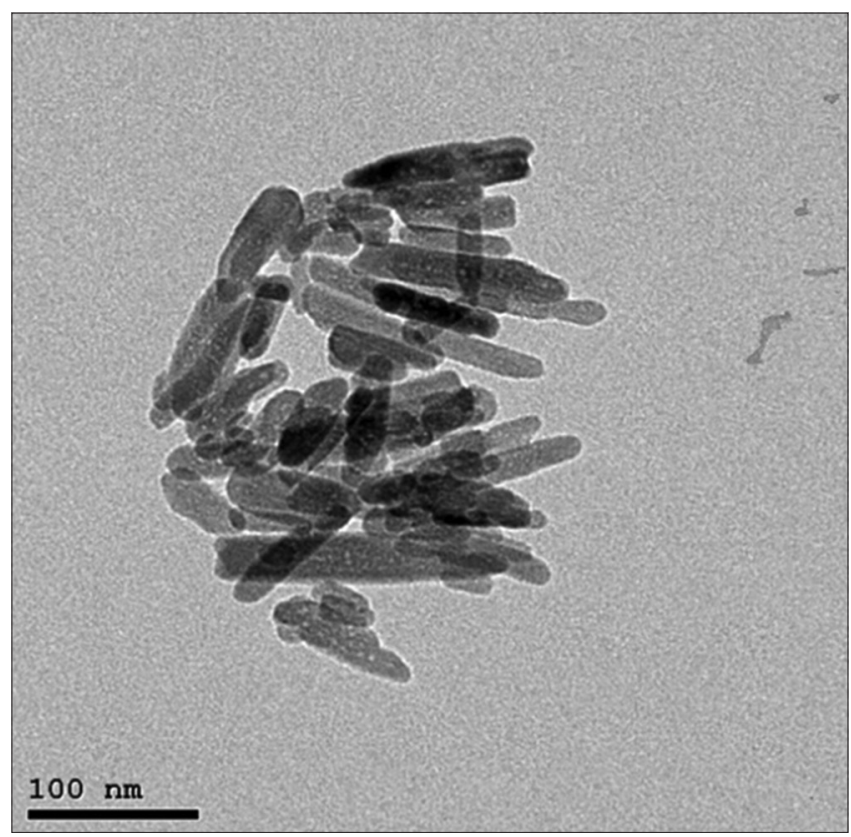

Figure 1: Transmission electron microscopy image analysis of the prepared hydroxyapatite nanoparticles

The investigation of the FT-IR of the main functional groups in the free HA, free coral calcium, and the mixture between them were represented in Figure 2. The FT-IR charts of the HA and the Mix showed phosphate ions vibrational modes at 472, 566, and $602 \mathrm{~cm}^{-1}$. While it was noticed bands identified at 960,1029 , and $1096 \mathrm{~cm}^{-1}$. In addition, one pronounced broad peak centered at 3435 and $3428 \mathrm{~cm}^{-1}$ in the charts of the HA and the Mix, respectively. Furthermore, both IR charts of the HA and the Mix possessed intensity bands seen at 875 and $1420 \mathrm{~cm}^{-1}$.

Mean and standard deviations values of the percentages of calcium remineralization (before and after application of remineralizing gel) for all groups are presented in (Table 1) and (Figure 3). The results showed a statistically significant difference between the control group (Group 10) and each of (Group 1), (Group 2), (Group 3), (Group 4), (Group 5), (Group 6),

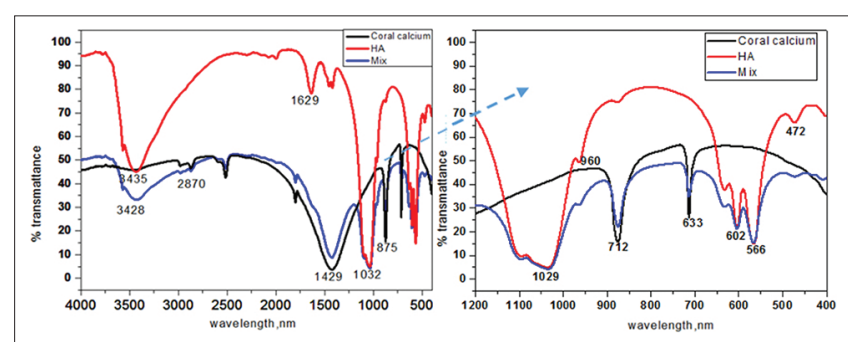

Figure 2: Fourier-transform infrared spectra of the synthesized hydroxyapatite nanoparticles, coral calcium, and the mixture

(Group 7), (Group 8), and (Group 9). Moreover, there was a statistically significant difference between (Group 2) and each of (Group 3), (Group 4), (Group 5), (Group 6), (Group 7), and (Group 9).

Table 1: Mean and SD of the percentage of calcium remineralization (after application of remineralizing gel) of the different groups

\begin{tabular}{|c|c|c|}
\hline Groups & $\begin{array}{l}\text { Percentage of calcium remineralization } \\
\text { Mean }\end{array}$ & SD \\
\hline Group 1 (10\% cc) & $38.62^{b}$ & 6.00 \\
\hline Group 2 (20\% cc) & $48.64^{\circ}$ & 5.95 \\
\hline Group 3 (30\% cc) & $39.06^{\mathrm{b}}$ & 6.19 \\
\hline Group 4 (10\% cc+HA mix) & $39.06^{b}$ & 7.09 \\
\hline Group 5 ( $20 \%$ cc+HA mix) & $33.04^{\mathrm{b}}$ & 8.27 \\
\hline Group 6 (30\% cc+HA mix) & $37.29^{\mathrm{b}}$ & 6.23 \\
\hline Group 7 (10\% cc+argon laser) & $35.38^{b}$ & 6.39 \\
\hline Group 8 ( $20 \%$ cc+argon laser) & $47.49^{\mathrm{c}}$ & 5.14 \\
\hline Group 9 (30\% cc+argon laser) & $36.20^{\mathrm{b}}$ & 4.45 \\
\hline Group 10 (control) & $7.26^{\mathrm{a}}$ & 3.67 \\
\hline$p$-value & $<0.001^{*}$ & \\
\hline
\end{tabular}

In addition, a statistically significant difference was found between (Group 8) and each of (Group 1), (Group 3), (Group 4), (Group 5), (Group 6), (Group 7), and (Group 9) where ( $p<0.001)$.

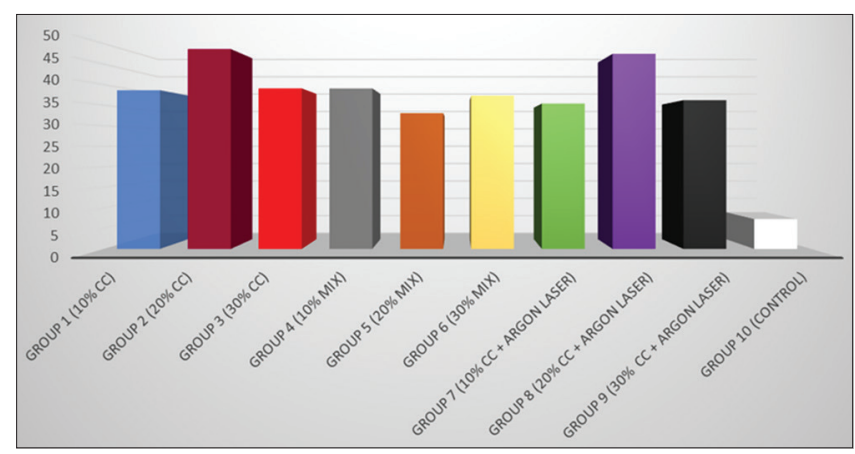

Figure 3: Representative histogram of calcium levels percentage of change for all groups before and after application of remineralizing gel

\section{Discussion}

The HAnanoparticles were synthesized through wet chemical precipitation approach. This technique is characterized by being simple, using inexpensive raw materials, and low reaction temperature. The synthesized HA was characterized using TEM and FT-IR analysis. The TEM image observes the morphologies of the particles and confirms that the particles fall into the nano-sized range. The FT-IR spectra confirmed the 
structural composition of the prepared HAnanoparticles, coral calcium, and a mixture of them [22].

The phosphate ions vibrational modes at 472 , 566 , and $602 \mathrm{~cm}^{-1}$ may attribute to $\mathrm{v}_{2}$ and $\mathrm{v}_{4}$ symmetric bending modes of $\mathrm{O}-\mathrm{P}-\mathrm{O}$ in phosphate ions. While the bands identified at 960,1029 , and $1096 \mathrm{~cm}^{-1}$ suggested corresponding $\mathrm{v}_{1}$-symmetric and $\mathrm{v}_{3}$-asymmetric stretching modes for the $\mathrm{P}-\mathrm{O}$ in Phosphate ions, these results are in agreement with those obtained previously [22]. The appearance of these bands in the chart of the mix indicated the presence and loading of $\mathrm{HA}$ in the mixture. In addition, one pronounced broad peak centered at 3435 and $3428 \mathrm{~cm}^{-1}$ in the IR charts of the HA and the Mix, respectively, assigned to the symmetric stretching mode of the hydroxyl group $(-\mathrm{OH})$. Furthermore, both IR charts of the HA and the mixture possessed intensity bands seen at 875 and $1420 \mathrm{~cm}^{-1}$ due to components of $v_{2}$ and $v_{3}$ symmetric modes of carbonate ions. The band appeared in the IR charts of coral calcium and Mix at $2390 \mathrm{~cm}^{-1}$ are attributed to the $\mathrm{C}-\mathrm{H}$ stretching modes originated from methyl group in the methylcellulose and $\mathrm{C}-\mathrm{H}$ coral calcium [22].

The enamel crystals start a demineralization process when the bacterial acids drop the $\mathrm{pH}$ below 5.5 (critical pH). A white spot lesion is detected in early phases as a result of loss of calcium and phosphate from surface and subsurface. The demineralization of crystals can be reversed on the condition that the acidogenic $\mathrm{pH}$ of the biofilm is buffered. Normal healthy saliva demonstrates a major role in helping to regain a remineralization favorable $\mathrm{pH}$ at the tooth surface by its buffering capacity due to its slight alkalinity and enriched mineral content [4].

The process of remineralization requires removal of the dietary carbohydrate and subsequent elevation in the $\mathrm{pH}$ of the biofilm to 7.0. When the $\mathrm{pH}$ is above the critical level (alkaline), demineralization will be reduced, the mineral begins to regain calcium and phosphate from saliva, and from other topical sources such as mouthwashes, toothpastes and dietary components, diffuses into the tooth and, with the help of remineralizing agents, builds on the surface. Newly formed crystal is composed of a layer of wellestablished minerals, together with deficient minerals. The crystal on the surface is less soluble to the attack of acid than the original HA crystals [23].

Coral calcium is calcium carbonate natural material with many other minerals which are essential for the human body; it increases the alkalinity of the enamel surface as well as enhancing remineralization of initial enamel lesion [24].

Therefore, in this study, coral calcium was tested as remineralizing agent in different concentrations and forms, whereby, it was used in $10 \%, 20 \%$, and 30 wt.\% concentrations using argon laser to increase the temperature so to enhance the precipitation of calcium into the enamel surface and in a combined form with nanohydroxyapatite to promote its remineralization process. The specimens were evaluated using EDXA to determine the amount of calcium after placing them in demineralizing solution and after remineralization.

The process of enamel demineralization depends on $\mathrm{pH}$, calcium, phosphate, and fluoride contents of teeth, these factors determine the level of mineral saturation. Thus, a sub-saturation condition can result in dissolution of HA crystals into the tooth and diffusion of calcium ions towards the enamel surface. A hyper-saturation of these ions on the enamel surface can lead to re-deposition of HA crystals known as remineralization, and consequently to the formation of an intact superficial layer on enamel surface [25].

The ability of the coral calcium to remineralize the demineralized enamel may be due to the precipitation of calcium ions of calcium carbonate from the coral calcium gel. The high calcium concentration changes the acidic $\mathrm{pH}$ into alkaline [26]. Moreover, the presence of silica promotes the adsorption of the gel to the tooth structure [27]. When the formulation contained only coral calcium as compared with combined HA nanoparticles mixed with coral calcium, they demonstrate less remineralization. This may be due to the possible mechanisms of HA nanoparticles in remineralization as the deposition of $\mathrm{HA}$ nanoparticles on the outer enamel surface will apparently block their pores thus minimize the diffusion of the minerals into the lesion [28]. Using argon laser was not effective in promoting the remineralization process. This may be due to their effect being limited to inhibition of cariogenic bacteria rather than the mechanism of remineralization itself [29]. The most powerful formula for remineralization was 20 wt. \% coral calcium, this may be due to the concentration of $30 \mathrm{wt} \%$ causing more early calcium precipitation without penetration into tooth, while the formula of concentration of $10 \mathrm{wt}$ \% may be not sufficient for adequate remineralization.

Bioactive glasses can help in prevention of enamel demineralization. For example, dentifrice with bioactive glasses was more effective than fluoride only in reducing enamel demineralization [5]. Coral calcium in all its forms showed the ability to remineralize the demineralized enamel which coincides with studies depends on the application of other calcium phosphatebased systems as casein phosphopeptide-ACP [4].

\section{Conclusion}

Coral calcium in all its forms showed the potential to remineralize initial enamel caries lesions. A suspension of 20 wt. \% coral calcium had the optimal concentration for remineralizing early enamel caries. Within the restrictions of the current study, we can conclude that coral calcium of optimal concentration 
could be beneficial in enhancing remineralization with regular usage.

\section{Recommendation for future works}

It is recommended to perform in vivo study about the remineralization effects of the coral calcium over a long period to get a more accurate result as it is a promising natural material.

\section{Acknowledgments}

Thanks are due to Dr. Roger Watson, Professor of Nursing, Faculty of Health Sciences, University of Hull, United Kingdom, for his encompassing support and help through the English editing.

\section{References}

1. Farooq I, Ali S, Siddiqui IA, Al-Khalifa KS, Al-Hariri M. Influence of thymoquinone exposure on the micro-hardness of dental enamel: An in vitro study. Eur J Dent. 2019;13(3):318-22. PMid:31618784

2. Ali S, Farooq I. A review of the role of amelogenin protein in enamel formation and novel experimental techniques to study its function. Protein Pept Lett. 2019;26(12):880-6. PMid:31364509

3. Alfaroukh R, Elembaby A, Almas K, Ali S, Farooq I, Bahammam $\mathrm{M}$, et al. Oral Biofilm formation and retention on commonly used dental materials: An update. Odonto-Stomatol Trop. 2018;41(164):29-34.

4. Farooq I, Bugshan A. The role of salivary contents and modern technologies in the remineralization of dental enamel: A review. F1000Res. 2020;9:171. PMid:32201577

5. Ali S, Farooq I, Al-Thobity AM, Al-Khalifa KS, Alhooshani K, Sauro $S$. An in-vitro evaluation of fluoride content and enamel remineralization potential of two toothpastes containing different bioactive glasses. Biomed Mater Eng. 2020;30(5-6):487-96. PMid:31594192

6. Margolis HC, Moreno EC. Kinetics of hydroxyapatite dissolution in acetic, lactic, and phosphoric acid solutions. Calcif Tissue Int 1992;50(2):137-43.

PMid:1315186

7. Pearce EIF, Moore AJ. Remineralization of softened bovine enamel following treatment of overlying plaque with a mineralenriching solution. J Dent Res. 1985;64(3):416-21. PMid:3855891

8. Kielbassa AM, Muller J, Gernhardt CR. Closing the gap between oral hygiene and minimally invasive dentistry: A review of the resin infiltration technique of incipient (proximal) enamel lesions. Br Dent J. 2009;207(9):425.

9. Wang J, Layrolle P, Stigter M, De Groot K. Biomimetic and electrolytic calcium phosphate coatings on titanium alloy: Physicochemical characteristics and cell attachment.
Biomaterials. 2004;25(4):583-92.

PMid: 14607496

10. Okazaki M, Takahashi J, Kimura H. Crystallinity patterns of fluoridated hydroxyapatites before and after incubation in acidic buffer solution. Caries Res. 1984;18(6):499-504.

PMid:6593121

11. Featherstone JD. Remineralization, the natural caries repair process--the need for new approaches. Adv Dent Res. 2009;21:4-7.

12. Vandiver J, Dean D, Patel N, Bonfield W, Ortiz C. Nanoscale variation in surface charge of synthetic hydroxyapatite detected by chemically and spatially specific high-resolution force spectroscopy. Biomaterials. 2005;26(3):271-83. PMid:15262469

13. Zaki DY, Zaazou MH, Khallaf ME, Hamdy TM. In vivo comparative evaluation of periapical healing in response to a calcium silicate and calcium hydroxide based endodontic sealers. Open Access Maced J Med Sci. 2018;6(8):1-5.

PMid:30159080

14. Hamdy TM, Mousa SM, Sherief MA. Effect of incorporation of lanthanum and cerium-doped hydroxyapatite on acrylic bone cement produced from phosphogypsum waste. Egypt J Chem. 2019;63:22-23.

15. Hamdy TM, Saniour SH, Sherief MA, Zaki DY. Effect of incorporation of $20 \mathrm{wt} \%$ amorphous nano-hydroxyapatite fillers in poly methyl methacrylate composite on the compressive strength. Res J Pharm Biol Chem Sci. 2015;6(3):975-8585.

16. Hamdy TM, El-Korashy SA. Novel bioactive zinc phosphate dental cement with low irritation and enhanced microhardness. e-J Surf Sci Nanotechnol. 2018;16:431-5.

17. Huang SB, Gao SS, Yu HY. Effect of nano-hydroxyapatite concentration on remineralization of initial enamel lesion in vitro. Biomed Mater. 2009;4(3):034104.

PMid:19498220

18. Kim MY, Kwon HK, Choi CH, Kim BI. Combined effects of nanohydroxyapatite and $\mathrm{NaF}$ on remineralization of early caries lesion. Key Eng Mater. 2007;330-332:1347-50.

19. Hamdy TM. Polymers and ceramics biomaterials in orthopedics and dentistry: Areview article. Egypt J Chem. 2018;61(1):723-30.

20. Orsini G, Procaccini M, Manzoli L, Giuliodori F, Lorenzini A, Putignano A. A double-blind randomized-controlled trial comparing the desensitizing efficacy of a new dentifrice containing carbonate/hydroxyapatite nanocrystals and a sodium fluoride/potassium nitrate dentifrice. J Clin Periodontol. 2010;37(6):510-7.

PMid:20507374

21. Yamagishi K, Onuma K, Suzuki T, Okada F, Tagami J, Otsuki M, et al. Materials chemistry: A synthetic enamel for rapid tooth repair. Nature. 2005;433(7028):819.

PMid: 15729330

22. Rodríguez-Lugo V, Karthik TV, Mendoza-Anaya D, RubioRosas E, Cerón LS, Reyes-Valderrama MI, et al. Wet chemical synthesis of nanocrystalline hydroxyapatite flakes: Effect of $\mathrm{pH}$ and sintering temperature on structural and morphological properties. R Soc Open Sci. 2018;5(8):180962.

PMid:30225084

23. Jones EM, Cochrane CA, Percival SL. The effect of $p H$ on the extracellular matrix and biofilms. Adv Wound Care. 2015;4(7):431-9.

PMid:26155386

24. Brockmann D, Janse M. Calcium and carbonate in closed marine aquarium systems. In: Advances in Coral Husbandry in Public Aquariums. Netherlands: Burgers' Zoo; 2008. p. 133-42. Available from: https://www.researchgate.net/ publication/228361538_Calcium_and_carbonate_in_closed_ 
marine_aquarium_systems. [Last accessed on 2020 Mar 25].

25. Pretty IA, Ingram GS, Agalamanyi EA, Edgar WM, Higham SM The use of fluorescein-enhanced quantitative light-induced fluorescence to monitor de and re-mineralization of in vitro root caries. J Oral Rehabil. 2003;30(12):1151-6.

PMid:14641655

26. Kumar VM, Govind GK, Siva B, Marish P, Ashwin S, Kiran M. Corals as bone substitutes. J Int Oral Health. 2016;8(1):96-102.

27. Ali Abdelnabi NK, Othman MS. Evaluation of re-mineralization of initial enamel lesions using nanohydroxyapatite and coral calcium with different concentrations. Egypt Dent J. 2019;65(2):3713-8

28. Huang S, Gao S, Cheng L, Yu H. Combined effects of nanohydroxyapatite and Galla chinensis on remineralisation of initial enamel lesion in vitro. J Dent. 2010;38(10):811-9.

PMid:20619311

29. Sonali Sharma LC, N. Hegde M, Sadananda V, Matthews B. Evaluation of efficacy of different surface treatment protocols by laser fluorescence: An in vitro study. Dent Oral Craniofacial Res. 2017;3(4):1-5. 